\title{
Pituitary-dependent hyperadrenocorticism in a shi tzu dog treated with twice-daily oral trilostane: a case report
}

\author{
Hyperadrenocorticismo hipófise dependente em um cão shi tzu \\ tratado com trilostane oral a cada 12 horas: relato de caso
}

\author{
Lucas Alécio Gomes ${ }^{1 *}$; Lívia Pesente de Lacerda ${ }^{2}$
}

\begin{abstract}
Hyperadrenocorticism can be defined as a chronic high circulating cortisol, and is a relatively common disease in dogs when compared to cats. Of dogs with naturally occurring HAC, 80 to $85 \%$ have pituitary-dependent hyperadrenocorticism (PDH), which is an excessive secretion of ACTH by the pituitary, causing bilateral adrenal hyperplasia and excessive secretion of glucocorticoids. More than $90 \%$ of dogs with PDH have a pituitary tumor. The aim of this article is to report a case of a dog, seven years old, female, Shi Tzu, that presented with panting, polyuria/polydipsia, polyphagia, pendulous abdomen and bilateral abdominal alopecia, and intermittent weakness in the pelvic limbs. Based on laboratorial and screening tests a pituitary-dependent hyperadrenocorticism was diagnosed and treated with twice-daily trilostane, orally. In the early monitoring period, ACTH test was performed with an unusual interval (to 30 days). In this case, the starting dose didn't show improvement in the cutaneous alterations, requiring an increase on the dosage.
\end{abstract}

Key words: Dog, hyperadrenocorticism, canine hyperadrenocorticism, trilostane

\section{Resumo}

Hiperadrenocorticismo (HAC) é uma doença relativamente comum em cães quando comparado aos gatos e pode ser definido como aumento persistente do cortisol na circulação sanguínea. Quanto ao tipo de manifestação o HAC hipófise-dependente ocorre em 80 a $85 \%$ dos casos, causando secreção excessiva de ACTH pela hipófise levando ao aumento bilateral das glândulas adrenais. Mais de 90\% dos casos de HAC hipófise-dependente (em cães) ocorrem devido a tumores na glândula. O objetivo deste trabalho é relatar o caso de uma cadela da raça Shi Tzu, com sete anos de idade, que apresentou respiração ofegante, poliúria/polidipsia, polifagia, abdome pendular, alopecia bilateral simétrica e fraqueza intermitente em membros pélvicos. Os exames laboratoriais de rotina associados aos testes de triagem confirmaram a suspeita de hiperadrenocorticismo hipófise dependente. $\mathrm{O}$ tratamento desde o início tem sido com trilostane com trilostane, via oral, a cada 12 horas, e o teste de estimulação com ACTH foi realizado em intervalo não usual durante o período de monitoração inicial (a cada 30 dias). Neste caso, a dose inicial de trilostane não demonstrou melhora em relação às alterações cutâneas e houve necessidade de aumento na dosagem.

Palavras-chave: Cão, hiperadrenocortiscismo, hiperadrenocorticismo canino, trilostane

1 Prof. Dr. PhD do Dept ${ }^{\circ}$ de Clínicas Veterinárias, Universidade Estadual de Londrina, UEL, Londrina, PR. E-mail: lucasalecio@ gmail.com

2 Discente de Graduação, Faculdade de Medicina Veterinária e Zootecnia, Universidade Federal do Mato Grosso do Sul, UFMS, Campo Grande, MS. E-mail: liviapesente@hotmail.com

* Author for corespondence 


\section{Introduction}

Hyperadrenocorticism (HAC) is a common condition in dogs and can be defined as the physical and biochemical changes that result from prolonged exposure to inappropriately high plasma concentrations of (free) cortisol, whatever its cause. The neurosurgeon Dr. Harvey Cushing described the clinical manifestations of humans with basophil adenomas of the pituitary gland in 1932, which is the reason by this disease is often called Cushing's syndrome. Years later, it was found that these tumors produced excess adrenocorticotropic hormone (corticotrophin, ACTH) with resultant bilateral adrenocortical hyperplasia (KOOISTRA, GALAC, 2010).

The development of clinical signs of glucocorticoid excess depends on the severity and duration of the exposure. The effects also vary among animals owing to interindividual differences in cortisol sensitivity. Corticosteroid administration causes prompt and sustained suppression of the hypothalamic-pituitary-adrenocortical axis. Depending on the dose and the intrinsic glucocorticoid activity of the corticosteroid, the schedule and duration of its administration, and duration of its administration, and the preparation or formulation, this suppression may exist for weeks or months after cessation of the corticosteroid administration (KOOISTRA, GALAC, 2010).

Of dogs with naturally occurring HAC, 80 to $85 \%$ have pituitary-dependent hyperadrenocorticism (PDH); that is, excessive secretion of ACTH by the pituitary, causing bilateral adrenal hyperplasia and excessive secretion of glucocorticoids. More than $90 \%$ of dogs with PDH have a pituitary tumor. However, the reported incidence of pituitary tumors in dogs with PDH varies tremendously depending on the pathologist investigation, as well as the microdissection capabilities and staining capacities of the laboratory performing the histologic examination. Ectopic form of hyperadrenocorticism is rare in dogs. The remaining 15 to $20 \%$ of cases of spontaneous hypercortisolism are $\mathrm{ACTH}$-independent and result from autonomous hypersecretion of glucocorticoids by an adrenocortical adenoma or adenocarcinoma (FELDMAN, 2011; HILL, 2011; RAMSEY, 2010).

HAC naturally occurring is a disease of middleaged to older dogs but can be seen in dogs ranging from 6 months to 20 years. The mean age at diagnosis is 11 years, and almost all dogs with HAC are older than 6 years of age. The incidence is much higher in dogs than in humans and cats and has been reported to be 1 to 2 cases per 1000 dogs per year. There is no sex predilection in dogs with $\mathrm{PDH}$. The disease occurs in all dog breeds, however, PDH seems to be more common in small dogs $(<20 \mathrm{~kg})$ beagles, boxers, dachshunds, German shepherds, poodles, and terriers are overrepresented. Adrenal-dependent hyperadrenocorticism (ADH) predominate in large breeds $(50 \%$ weigh $>20 \mathrm{~kg})$, dachshunds, German shepherds, Labrador retriever, poodles, and terriers are overrepresented (HILL, 2011; KOOISTRA, GALAC， 2010; MELIÁN, PÉREZ-ALENZA; PETERSON, 2010).

Clinical history is related to polyuria/polydipsia (PU/PD), polyphagia, pendulous abdomen, excessive bruising, panting, alopecia, clitoral hypertrophy, testicular atrophy, anestrus, weakness/ lethargy, exercise intolerance, muscle atrophy, obesity. In the physical examination the animal may demonstrate thin skin, bilaterally symmetric alopecia, hepatomegaly, pioderma, abdominal enlargement, clitoral hypertrophy, testicular atrophy, bruising, muscle wasting, seborrhea, calcinosis cutis, hyperpigmentation, comedones (HILL, 2011; MELIÁN, PÉREZ-ALENZA; PETERSON, 2010).

The diagnosis of HAC should always be based initially on a clinical suspicion gained from the history and physical examination. To further support the clinical suspicion, each dog should undergo clinicopathologic studies (i.e. complete blood count, serum chemistry profile, and complete urinalysis with culture). The most common finding in biochemistry tests in dogs with HAC is a high serum 
alkaline phosphatase (ALP) activity. This finding is present in $85 \%$ to $95 \%$ of HAC dogs. Additionally, abdominal ultrasound is recommended in any dog with suspected HAC. Choi, Kim and Yoon (2011) conducted a study which they performed the measurement of adrenal glands in 189 normal dogs and 22 dogs with $\mathrm{PDH}$, involving 14 different small breed dogs, and they detected that in normal animals the median of the normal gland width was $4.2 \mathrm{~mm}$. Regarding specifically to Shi Tzu dogs, they found the median width in normal adrenal glands was $4.4 \mathrm{~mm}$. All these tests help make a presumptive diagnosis of HAC and are also helpful to alert the clinician to any concomitant medical problems (GILOR, GRAVES, 2011; HILL, 2011; FELDMAN, 2011; MELIÁN, PÉREZ-ALENZA; PETERSON, 2010).

Complete urinalysis is an important component when evaluating any dog with PU/PD. Approximately $85 \%$ of dogs with HAC have low urine specific gravity $(<1.020)$. Proteinuria and systemic hypertension are other common problems recognized in dogs with untreated Cushing's syndrome when compared to treated patients, and they may represent a "cause-and-effect" relationship. Evidence of proteinuria should prompt the clinician to evaluate the dog's blood pressure and to submit urine for culture. A protein-losing glomerulopathy is common in dogs with Cushing's syndrome, but the severity of proteinuria is generally less than that typically seen in dogs with hypoalbuminemia or hypoproteinemia (GILOR, GRAVES, 2011; MELIÁN, PÉREZ-ALENZA; PETERSON, 2010; PETERSON, 2007; FORRESTER et al, 2003)

Dogs with HAC are prone to urinary tractinfection (UTI) probably from chronic immunosuppression and a persistent bladder overdistention. In one study involving dogs with hyperadrenocorticism, UTI was present in $46 \%$ of dogs with hyperadrenocorticism (FORRESTER et al, 2003). Therefore, a urine culture using a sample obtained by cystocentesis should be performed even if clinical signs or urinalysis do not show the classical presentation for
UTI (MELIÁN, PÉREZ-ALENZA, PETERSON, 2010).

Urine cortisol to creatinine ratio (UCCR) is a commonly used screening test that has a high sensitivity but low specificity, and is more important to rule out hyperadrenocorticism (MELIÁN, PÉREZ-ALENZA, PETERSON, 2010).

For the specific approach to a dog with presumed hyperadrenocorticism, the sensitivity of the pituitaryadrenal-axis is usually tested by administering lowdose-dexamethasone intravenously (LDDS). The finding of a serum cortisol concentration higher than $40 \mathrm{nmol} / \mathrm{L}$ at 8 hours after dexamethasone administration, indogs with physical and biochemical changes pointing to hyperadrenocorticism, confirm the disease (KOOISTRA, GALAC, 2010). Another confirmatory test is ACTH stimulation; sensitivity of this test for dogs with $\mathrm{PDH}$ and $\mathrm{ADH}$ is $87 \%$ and $60 \%$ respectively; a $15 \%$ chance of false-positive exists with chronic nonadrenal illness (HILL, 2011).

Once the diagnosis of HAC is done, the next step is to differentiate between $\mathrm{PDH}$ and $\mathrm{ADH}$. Some tests and interpretations like LDDS, ACTH stimulation test and abdominal ultra-sound and/ or CT or MRI scans are the key to do these differentiations. In the LDDS when suppression is $>$ than $50 \%$, its indicate that the disease is $\mathrm{PDH}$; when the suppression is $<$ than $50 \%$ both $\mathrm{PDH}$ or ADH may be cause of the problems, and imaging modalities will help in differentiation (ex: both adrenal gland increased in size indicate PDH; just one adrenal gland increased in size and the other one normal or decreased indicates ADH) (GILOR, GRAVES, 2011; HILL, 2011; FELDMAN, 2011; MELIÁN, PÉREZ-ALENZA; PETERSON, 2010).

Hyperadrenocorticism can be treated medically or surgically (FELDMAN, 2011; MELIÁN, PÉREZALENZA, PETERSON, 2010; HELM et al., 2011; HILL, 2011). In this article, the treatment will be focused in medical modality, particularly trilostane. The first report of the use of trilostane in canine HAC was in 1998. Most dogs with PDH are treated 
medically in an attempt to decrease ACTH secretion (i.e., Selegiline), to inhibit the synthesis of adrenal cortex hormones (i.e., trilostane or ketoconazole), or to cause partial or complete necrosis of the adrenal cortex (i.e., mitotane). Mitotane and trilostane are both effective. Dogs seem to tolerate trilostane better than mitotane; however, both treatments have potential serious side effects and the veterinarian and the owner should be aware of this. Medical treatment aimed at the adrenal cortex (trilostane or mitotane) to lower plasma cortisol concentrations may increase ACTH secretion. The starting dose may range from $0.5 \mathrm{mg} / \mathrm{kg}$ twice daily to $20 \mathrm{mg} / \mathrm{kg}$ once daily, however, based on some studies seems to be logical to recommend a starting dose in the range 2 to $5 \mathrm{mg} / \mathrm{kg}$ once to twice daily (FELDMAN, 2011; HELM et al, 2011; MELIÁN, PÉREZ-ALENZA, PETERSON, 2010; RAMSEY, 2010).

One of the consistent features of the most clinical studies published about the use of trilostane in canine $\mathrm{HAC}$ is the frequency of monitoring. However, the basis for this frequency is not clear. The caution of the early studies may not be appropriate now that more is known about the response to trilostane. In particular, the clinical signs and cortisol concentration continue to improve in most dogs in the first month. Performing an ACTH stimulation test ten to fourteen days after starting therapy may not be so useful because changing the dose at this stage would risk increasing the dose of trilostane too early. A review consultation could adequate, and an ACTH stimulation test only performed if adverse effects have been noted. Monthly monitoring for the first three months, followed by monitoring every three months for the first year and every four to six months thereafter may well be adequate (RAMSEY, 2010). Considering this elucidations, he aim of this article is to report a case of a dog, seven years old, female, Shi Tzu, that presented with a pituitary-dependent hyperadrenocorticism, treated with twice-daily trilostane, orally, which the ACTH test is being performed in an unusual interval for monitoring (30 days interval).

\section{Case Report}

\section{Results, discussion and conclusions}

The aim of this article is to report the case of an intact female Shi Tzu dog, six-year-old, which was admitted to a Veterinary Teaching Hospital with the history of polyuria / polydipsia (PU/ PD), polyphagia, bilateral symmetrical alopecia, superficial folliculitis and sometimes lethargy and panting. Second to the owner, the signs were evident for at least three months. During the animal lifetime no use of any medicine was necessary. On the physical examination was detected abdominal distention, bilateral symmetric alopecia (mainly in the flank), cutaneous calcinosis in ventral left abdomen, telangiectasia and diffuse comedones (Figure 1-A, B). According to this, the first suspect differential diagnosis was hyperadrenocorticism.

The differential diagnosis in dogs with PU/PD is a challenge and includes many diseases like kidney failure, diabetes mellitus, hyperadrenocorticism, liver failure, pyometra, hypoadrenorticism, and others. Therefore, the complementary exams are the key to exclude many differentials and keep HAC as the first one on the top differentials. Based on this, routine complementary exams were done and the findings were: low urinary density (1.020), no proteinuria, high phosphatase alkaline (820.0 U/L), high alanine aminotransferase (510.0 $\mathrm{U} / \mathrm{L})$, and hypercholesterolemia $(580.0 \mathrm{mg} / \mathrm{dL})$; BUN, creatinine, blood glucose were normal. At the abdominal ultra-sound the only abnormality detected, according to the sonographer report, was the increase in volume of the adrenal glands (diameters: right adrenal measuring 23.0 x 7.0 millimeters (mm); left adrenal measuring 20.0 $\mathrm{x} 6.0 \mathrm{~mm}$ ). Because the urinary tract infection is a common finding in dogs with $\mathrm{HAC}$, a sterile urine sample was obtained and sent to culture and antibiotic resistance test, and the results were negative. 
Figure1. Photograph showing bilateral symmetrical alopecia and pendulous abdomen (A); presence of cutaneous asthenia in abdominal skin and cutaneous calcinosis (arrow - B).

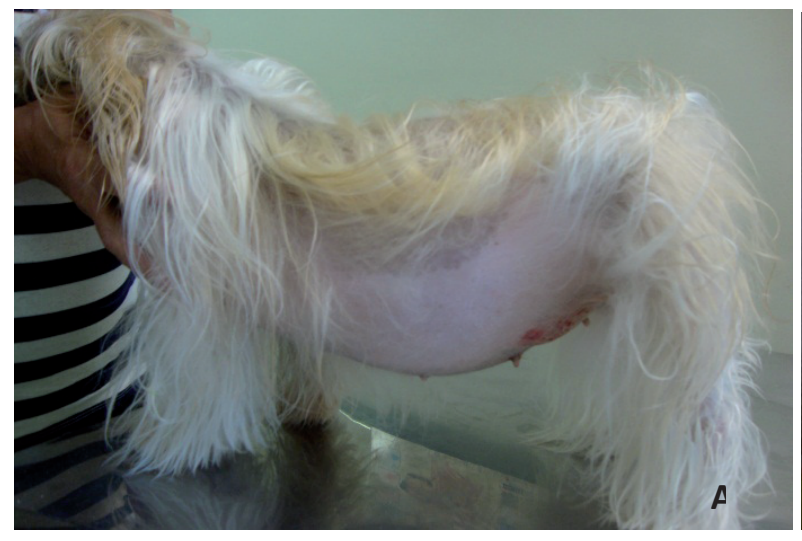

Source: Elaboration of the authors.

Information's obtained from the tests were very important on helping to exclude some differential diagnosis. For example, diabetes mellitus need to be associated to marked elevation on blood glucose and glycosuria, changes that were not observed in this case; consequently diabetes mellitus as the cause of PU/PD were excluded from the top differentials. The same logical approach should be used to rule out the other condition cited here, in other words, absence of azotemia, icterus and alteration on biliary acids, vaginal discharge or uterine increase in size (on the ultra-sound evaluation), lethargy, gastrointestinal signs, excluded most of differentials diagnosis listed (FELDMAN, 2011; HILL, 2011; GILOR, GRAVES, 2011; MELIÁN, PÉREZ-ALENZA, PETERSON, 2010; KOOISTRA, GALAC, 2010).

The diagnosis of hyperadrenocorticism in this case was based on the history, clinical signs and specific tests to evaluate the pituitary-adrenal-axis. When the clinician suspect that a dog is presenting hyperadrenocorticism, clinical pathology exams are very important as part of the diagnostic plan; for example, a dog with HAC usually has higher alkaline phosphatase, thus, at least this alteration is expected to be present in a dog which HAC is suspected. Therefore, to give the next step in the clinical approach, some aspects are mandatory in most of the cases, in other words,

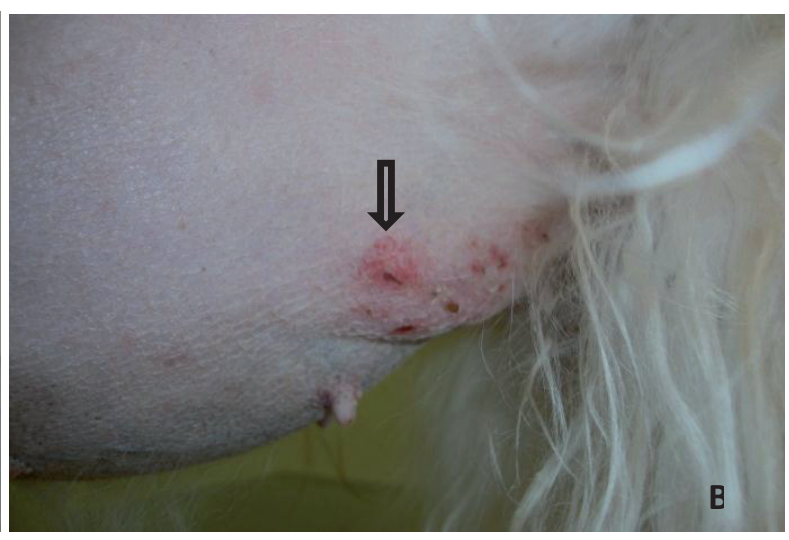

the decision to perform specific tests to evaluate the hypothalamus-pituitary-adrenal-axis, requires in most of the cases the presence of some physical and clinicopathological alterations, as the presence of low urinary density, high liver enzymes, and elevation in serum cholesterol, including of course, PU/PD in the history. These considerations were the guidelines in this Shi Tzu dog clinical approach, once the animal have presented all the features compatible with the diagnosis of HAC; considering this, and being in concordance with what is recommended in the literature, the next adopted step in this case, was the requirement of the tests to evaluate the hypothalamus-pituitary-adrenalaxis (FELDMAN, 2011; HILL, 2011; GILOR, GRAVES, 2011; MELIÁN, PÉREZ-ALENZA, PETERSON, 2010; KOOISTRA, GALAC, 2010).

However, one limitation involving the steps in clinical approach was the absence of the urine cortisol to creatinine ratio (UCCT) in this case. Although UCCT is important for the initial diagnosis of HAC, this screening test was not done because some limiting factors were highlighted by the owner, like financial constraints, the need to collect urine at home, and the possibilities of falsepositive results.

All findings (history, physical examination and laboratorialtests); have sustained that it was a possible 
case of pituitary-dependent hyperadrenocorticism, and following that considerations, more specific tests to evaluate the hypothalamus-pituitary-adrenal axis were performed (low-dose-dexamethasone suppression test [LDDST] and ACTH stimulation test) to confirm the disease. The cortisol results (serum cortisol) in the low-dose-dexamethasone suppression test were: $114.6 \mathrm{ng} / \mathrm{mL}$ (basal) and 2.6 $\mathrm{ng} / \mathrm{mL}$ (eight hours after), and in ACTH stimulation test was: $112 \mathrm{ng} / \mathrm{mL}$ (basal) and $176.6 \mathrm{ng} / \mathrm{mL}$ (one hour after). According to the reference values provided by the laboratory that performed the tests, basal cortisol levels was increased on the LDDST and in the ACTH test, which is compatible with HAC; however, eight hours after dexamethasone administration, the serum cortisol decreased drastically being bellow the range considered; this adrenal suppression 8 hours later, in the majority of the cases is expected for normal dogs, although, $5 \%$ of the dogs with PDH may show a response compatible with what is expected for a normal dog, which is plausible to consider for the Shi Tzu dog reported here. Regarding to the values of serum cortisol after ACTH administration, they were borderline, which neither exclude nor confirm the disease, although might happen in some cases of HCA (HILL, 2011; GILOR, GRAVES, 2011; MELIÁN, PÉREZ-ALENZA, PETERSON, 2010; KOOISTRA, GALAC, 2010).

$\mathrm{HAC}$ is relatively common in dogs, and $80-85 \%$ of the cases are pituitary-dependent (FELDMAN, 2011; HILL, 2011; RAMSEY, 2010); Breed, body weight, clinical findings and abdominal ultrasound are aspects that require attention in the clinical approach for dogs presenting characteristics compatible with HAC, because they help to differentiate between PDH and ADH. Considering this, the patient presented here is prone to have $\mathrm{PDH}$ instead of ADH, mainly if we look forward to abdominal ultra-sound results which bilaterally mild adrenal increasing were observed.

In this case the differentiation between PDH and $\mathrm{ADH}$ was based on abdominal ultra-sound results (adrenal glands increased in size - considering that the median width of normal adrenal glands for Shi Tzu dogs as $4.4 \mathrm{~mm}$ (CHOI, KIM, YOON, 2011) and ACTH stimulation test; basal values on the first (before starting trilostane treatment) and second samples (after starting trilostane treatment) were above the ranges; however, the values 1 hour after the ACTH administration were within normal ranges in first sample, but was very higher in the second sample analysis, which is consistent with PDH.

Considering all the features and findings described previously, the treatment adopted was trilostane (the starting dose was $2 \mathrm{mg} / \mathrm{kg}$ twice-daily, orally). Four days after starting the use of trilostane, the owner reported that the animal has presented mild decreasing in water and food ingestion, keeping these changes until the performance of another ACTH stimulation test, which was done thirty days after the treatment beginning; regarding to this, the results were: $89.6 \mathrm{ng} / \mathrm{mL}$ (basal) and $500 \mathrm{ng} / \mathrm{mL}$ (one hour after). These values are both increased (especially the second - very high response) and this sustained the diagnosis of HAC, reinforcing that since the beginning, the diagnosis was correct. Based on this result, the dose was increased to $3 \mathrm{mg}$ / $\mathrm{kg}$ twice-daily, orally. According to the owner, after the increasing in trilostane dosage, the dog has kept the decrease in water and food intake and hair falling has stopped, but no improvement has been observed on other skin abnormalities, abdominal distention and cutaneous calcinosis until that moment (three weeks later after the elevation of the dose). The next step after changing the dose will be performing another ACTH stimulation test, respecting the thirty days interval. The reason for using this unusual interval is based on recommendation from Ramsey (2010); the respective author suggest a longer interval to evaluate the action of trilostane because he consider that performing an ACTH stimulation test ten to fourteen days after starting or changing therapy may not be so useful because changing the dose at this stage would risk increasing the 
dose too early. The treatment was instituted based on the recommendations for the starting dose that may range from $0.5 \mathrm{mg} / \mathrm{kg}$ twice-daily to $20 \mathrm{mg} /$ $\mathrm{kg}$ once daily. The response of the patient has been mild until now ( \pm 50 days of treatment) and the dog showed decreasing in water and food intake, but no other improvement regard to the physical alterations described previously (bilaterally symmetrical alopecia, cutaneous calcinosis, pendulous abdomen and telangiectasia) were observed. From the owner expectations, the resolution of PU/PD has been a positive "feedback", once this clinical alteration was a cause of distress to him (FELDMAN, 2011; HILL, 2011; KOOISTRA, GALAC, 2010; RAMSEY, 2010).

It is well-recognized that the response to trilostane treatment may be individual and/or dose dependent, and in some cases there is no response. PU/PD resolution (partial or total) after 7 to 10 days of starting trilostane should be notice by the owner and indicates that the medicine is working; this change were documented here and represents a good beginning. However, the resolution of dermatological problems may take several months to happen after starting the treatment (FELDMAN, 2011; HILL, 2011; KOOISTRA, GALAC, 2010; RAMSEY, 2010). Therefore, more time is necessary to conclude if we will have better results using trilostane as the mentioned starting dose, or if will be necessary change the protocol as increasing the dose and/or intervals of administration in this case. Despite this consideration, the animal is responding to treatment and probably the benefits will be greater as long as trilostane is maintained; comparing trilostane and mitotane, the first one has the advantage to be safer when compared to the second one, which provides more possibilities regard to dose regimen and sometimes represents a better option to owner acceptance for the treatment.

\section{References}

CHOI, J.; KIM, H.; YOON, J. Ultrasonographic adrenal gland measurements in clinically normal small breed dogs and comparison with pituitary-dependent hyperadrenocorticism. Journal of Veterinary Science, Seoul, v. 73, n. 8, p. 985-989, 2011.

FELDMAN, E. C. Evaluation of twice-daily lower-dose trilostane treatment administered orally in dogs with naturally occurring hyperadrenocorticism. Journal of the American Veterinary Medical Association, New York, v. 238, n. 11, p. 1441-1451, 2011.

FORRESTER, S. D.; MARTÍNEZ, N. I.; PANCIERA, D. L.; MOON, M. L.; PICKETT, C. R.; WARD, D. L. Absence of urinary tract infection in dogs with experimentally induced hyperadrenocorticism. Research in Veterinary Science, Oxford, v. 74, n. 2, p. 179-182, 2003.

GILOR, C.; GRAVES, T. K. Interpretation of laboratory tests for canine Cushing's syndrome. Topics in Companion Animal Medicine, Philadelphia, v. 26, n. 2, p. 98-108, 2011.

HELM, J. R.; MCLAUCHLAN, G.; BODEN, L. A.; FROWDE, P. E.; COLLINGS, A. J.; TEBB, A. J.; ELWOOD, C. M.; HERRTAGE, M. E.; PARKIN, T. D. H.; RAMSEY, I. K. A comparison of factors that influence survival in dogs with adrenal-dependent hyperadrenocorticism treated with mitotane or trilostane. Journal of Veterinary Internal Medicine, Malden, v. 25, n. 2, p. 251-260, 2011.

HILL, K. Hyperadrenocorticism. In: CÔTÉ, E. Clinical veterinary advisor- dogs and cats. $2^{\text {nd }}$ ed. St. Louis, Missouri: Elsevier Mosby, 2011, p. 548.

KOOISTRA, H. S.; GALAC, S. Recent advances in the diagnosis of cushing's syndrome in dogs. Veterinary Clinics of North America - Small Animal, Philadelphia, v. 40, n. 2 , p. $259-267,2010$.

MELIÁN, C.; PÉREZ-ALENZA, M. D.; PETERSON, M. E. Hyperadrenocorticism in dogs. In: ETTINGER, S. J.; FELDMAN, E. C. Textbook of veterinary internal medicine - diseases of the dog and cat. $7^{\text {th }} \mathrm{ed}$. St. Louis, Missouri: Saunders Elsevier, 2010, p. 1816-1840.

PETERSON, M. E. Diagnosis of hyperadrenocorticism in dogs. Clinical Techniques in Small Animal Practice, Philadelphia, v. 22, n. 1, p. 2-11, 2007.

RAMSEY, I. K. Trilostane in dogs. Veterinary Clinics of North America - Small Animal, Philadelphia, v. 40, n. 2, p. 269-283, 2010. 
